\title{
Regional differences in tissue oxygenation during cardiopulmonary bypass for correction of congenital heart disease in neonates and small infants: Relevance of near-infrared spectroscopy
}

\author{
Mathias Redlin, MD, ${ }^{a}$ Andreas Koster, MD, ${ }^{a}$ Michael Huebler, MD, ${ }^{b}$ Wolfgang Boettcher, ECCP, ${ }^{c}$ Nicole Nagdyman, MD, \\ Roland Hetzer, MD, ${ }^{\mathrm{b}}$ Hermann Kuppe, MD, ${ }^{a}$ and Wolfgang $\mathrm{M}$. Kuebler, $\mathrm{MD}^{\mathrm{a}, \mathrm{e}}$
}

Objective: Cardiac surgery with cardiopulmonary bypass for correction of congenital heart disease in neonates and small infants is associated with considerable neurologic sequelae. We assessed the extent to which mixed venous oxygen saturation as a measure for adequacy of perfusion, reflects the oxygenation status of upper and lower body compartments. Moreover, we evaluated potential benefits of near-infrared spectroscopic monitoring of regional tissue oxygenation.

Methods: Twenty patients (body weight $<10 \mathrm{~kg}$ ) undergoing open cardiac procedures with cardiopulmonary bypass were enrolled. Blood samples were obtained in parallel from inferior and superior caval vein cannulas and mixed venous line and assessed for venous oxygen saturation and lactate levels. Data were compared to simultaneously measured tissue oxygenation indices obtained by near-infrared spectroscopy from brain and lower limb.

Results: Venous oxygen saturation was lower and lactate concentration higher in blood from superior relative to inferior venous line. Mixed venous oxygen saturation correlated with venous oxygen saturation from inferior venous line and tissue oxygenation index of lower limb. No correlation was found between mixed venous oxygen saturation and venous oxygen saturation from superior venous line or cerebral tissue oxygenation index.

Conclusion: In neonates and small infants undergoing cardiac surgery with cardiopulmonary bypass, considerable regional differences exist in venous oxygen saturation.

From the Departments of Anesthesia, Cardiothoracic and Vascular Surgery, Perfusion, ${ }^{\mathrm{c}}$ and Congenital Heart Disease, ${ }^{\mathrm{d}}$ Deutsches Herzzentrum Berlin, Berlin, Germany, and the Institute of Physiology, Charité-Universitaetsmedizin Berlin, Berlin, Germany.

NIRO-200 was kindly provided by Hamamatsu Photonics Deutschland $\mathrm{GmbH}$, Herrsching am Ammersee, Germany.

Received for publication Oct 8, 2007; accepted for publication Dec 17, 2007.

Address for reprints: Andreas Koster, MD Department of Anesthesia, Deutsches Herzzentrum Berlin, Augustenburger Platz 1, D13353 Berlin, Germany (E-mail: koster@ dhzb.de).

J Thorac Cardiovasc Surg 2008;136:962-7 $0022-5223 / \$ 34.00$

Copyright $(\subset) 2008$ by The American Association for Thoracic Surgery

doi:10.1016/j.jtcvs.2007.12.058
Mixed venous oxygen saturation primarily represents lower-torso oxygen status but poorly reflects and systematically overestimates upper-body oxygenation. Near-infrared spectroscopy yields additional information on regional oxygenation and may be valuable in early and sensitive detection of regional malperfusion in critical organs such as the brain.

$\mathrm{R}$ ecent improvements in cardiopulmonary bypass (CPB), surgical techniques, and intensive care have facilitated complex surgical procedures and perfusion for the correction of congenital heart disease (CHD) in even the smallest neonates, with low perioperative mortalities under 3\%. ${ }^{1}$ Incidences of neurologic complications after CPB in neonates and infants remain high, however, and neurologic sequelae have been reported in as many as $26 \%$ of patients. ${ }^{2}$ Neonates and young infants with complex CHD who have undergone open procedures with CPB still exhibit neurologic abnormalities approximately 5 years after the initial surgery, with hypotonia and developmental delay reported in $28.4 \%$ at age of school entry. ${ }^{3}$ Seven years after surgical correction, children with cyanotic cardiac defects remain at increased risk for attentional dysfunction in the field of executive control, and these attentional deficits are correlated with the durations of aortic crossclamping and $\mathrm{CPB} .{ }^{4}$ Incomplete cerebral ischemia and regional tissue hypoxia have been implicated as 


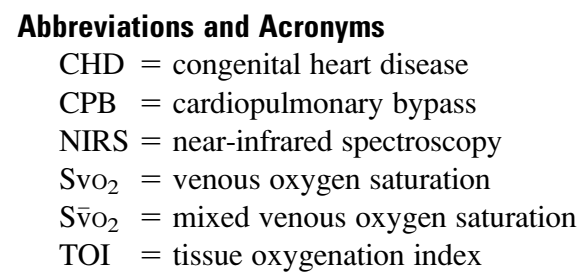

potential mechanisms underlying neurologic damage after CPB. ${ }^{5}$ This notion is supported by a close correlation between the perioperative arterial and cerebral blood oxygenations and the risk for postoperative brain damage in neonates. $^{6,7}$

To date, the only commonly used online-monitored parameter for the quality of perfusion and oxygenation during $\mathrm{CPB}$ in neonates and small infants is the mixed venous oxygen saturation $\left(\mathrm{S}_{\bar{v}} \mathrm{O}_{2}\right)$, as optically measured in the common venous line of the CPB system. ${ }^{8}$ The $\mathrm{S}_{\bar{v}}{ }_{2}$ is, however, a poor predictor of regional oxygenation levels in different organs and compartments of the body. ${ }^{9,10}$ Physiologically, regional inhomogeneities in tissue oxygenation can be attributed to organ-specific differences in tissue perfusion, in the regulation of vasomotor tone, in local diffusion distances, or in oxygen consumption. This situation is further complicated during surgical correction of $\mathrm{CHD}$, because preexisting malformations of the vascular system-including hypoplastic vessels, shunts, or collateralization-as well as impaired arterial inflow or venous drainage through the CPB cannulas may cause additional inhomogeneities of perfusion.

Recently, near-infrared spectroscopy (NIRS), a noninvasive method for transcutaneous measurement of oxyhemoglobin and deoxyhemoglobin concentrations in tissue, has increasingly been used to monitor cerebral oxygenation during CPB. ${ }^{11}$ The use of multiple sensor-detector systems allows in addition the comparison of regional tissue oxygenations, such as between the head and the flank ${ }^{12}$ or between different cerebral areas. ${ }^{13}$ In a recent case report, we documented regional malperfusion in a patient with complex aortic anatomy by means of simultaneous transcranial and lower torso NIRS monitoring. ${ }^{14}$ This investigation was performed to assess systematically the utility of regional oxygenation monitoring by NIRS relative to that of $\mathrm{S}_{\overline{\mathrm{V}}}{ }_{2}$ measurements during CPB in neonates and small infants undergoing surgical correction of CHD.

\section{Materials and Methods}

After approval was obtained from the local ethics committee and informed consent was obtained from the parents, 20 neonates and small infants (body weight $<10 \mathrm{~kg}$ ) undergoing surgical correction of CHD were enrolled in this prospective study. Patients with a diagnosis of persistent left upper caval vein were excluded from participation.

\section{Near-infrared Spectroscopy}

A near-infrared spectrometer (NIRO-200; Hamamatsu Photonics KK, Hamamatsu City, Japan) equipped with two independent emitter-sensor pairs was used for simultaneous measurement of regional oxygenations in the brain and in skeletal muscle of the lower torso. After induction of anesthesia, the first pair of NIRS optodes was positioned noninvasively on the patient's forehead with a spatial separation of $4 \mathrm{~cm}$ and an estimated optical path length of 15.4 $\mathrm{cm}$ between the emission and detection probes. ${ }^{15}$ A second pair of optodes was placed on the right thigh with an estimated optical path length of $14.4 \mathrm{~cm}$. Light was generated by three pulsed laser diodes at wavelengths of 775,810 , and $850 \mathrm{~nm}$, respectively, and emitted into the tissue through the source optode. Backscattered light from the tissue was collected by the detection probe equipped with a dual-segmented photodiode chip. With the spatially resolved spectroscopy method, the tissue oxygenation index (TOI) was calculated from measured changes of light attenuation along the intersegmental distance of the chip. ${ }^{16,17}$ The TOI is the ratio of oxygenated to total hemoglobin and thus reflects mean hemoglobin oxygen saturation within the scanned tissue section.

\section{CPB and Surgery}

In all cases, CPB was performed with a S3 mast-mounted roller pump console (Stöckert Instrumente $\mathrm{GmbH}$, Munich, Germany), which provided short tubing connections in our circuit consisting of tubing with $4.76 \mathrm{~mm}$ (16 inch) inner diameter in the entire system, with the exception of the roller pump segment of the arterial pump, which consisted of silicone rubber tubing with $6.35 \mathrm{~mm}(0,25 \mathrm{inch})$ inner diameter. The entire extracorporeal circuit, incorporating the Capiox RX05 hollow-fiber membrane oxygenator (Terumo Deutschland GmbH, Eschborn, Germany) and an arterial line filter (Dideco D736; Dideco SpA, Mirandola, Italy), had a total priming volume of $200 \mathrm{~mL}^{18}$

The patients' CHD diagnoses and the surgical procedures are summarized in Table 1. During CPB, a systemic hemoglobin concentration less than $8 \mathrm{~g} / \mathrm{L}$, corresponding to a hematocrit of approximately $24 \%$, was considered the critical trigger for the transfusion of red blood cells.

\section{Data Acquisition and Statistical Analysis}

During CPB, TOI was continuously recorded at the forehead and the right thigh by spatially resolved NIRS. Blood samples ( $0.3 \mathrm{~mL}$ each) were obtained at 30-minute intervals from both the inferior and the

\section{TABLE 1. Diagnoses and surgical procedures}

\begin{tabular}{llr}
\hline \multicolumn{1}{c}{ Diagnosis } & \multicolumn{1}{c}{ Procedure } & No. \\
\hline Atrial septal defect & Patch closure & 1 \\
$\begin{array}{l}\text { Ventricular septal defect } \\
\text { Complete atrioventricular } \\
\quad \text { channel }\end{array}$ & Patch closure & 5 \\
2-patch reconstruction & 4 \\
$\quad$ great arteries & Arterial switch operation & 2 \\
Tetralogy of Fallot & Correction & \\
ALCAPA & Correction & 3 \\
Double-outlet right ventricle & Correction & 3 \\
\hline
\end{tabular}

ALCAPA, Anomalous origin of left coronary artery from pulmonary artery. 

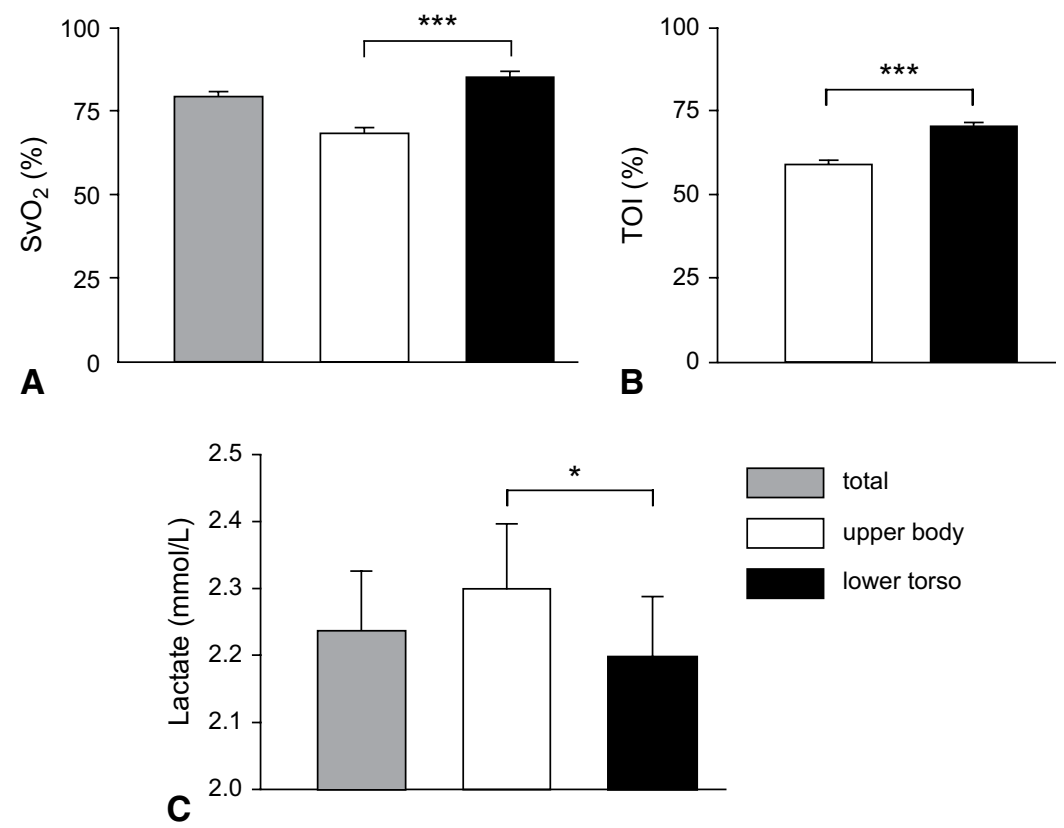

Figure 1. Oxygenation in upper and lower body compartments during CPB in neonates. Group data of venous oxygen saturation $\left(\mathrm{SvO}_{2}, \mathrm{~A}\right)$ and lactate (C) determined in blood drawn from superior cannula (black bars), inferior cannula (white bars), or mixed venous line (gray bars) show higher oxygen extraction and lactate levels in upper body than in lower torso. Similarly, tissue oxygenation index (TOI, B) determined in lower limb exceeded simultaneously measured value in brain. Each bar is mean \pm SEM from 55 measurements in 20 patients; asterisk represents $P<.05$; triple asterisk represents $P<.001$. superior venous lines near the patient and in parallel from the mixed venous line of the CPB circuit. All samples were immediately analyzed for blood gas values (Rapidlab 865; Siemens Healthcare Diagnostics Inc, Deerfield, Ill), venous oxygen saturation $\left(\mathrm{SvO}_{2}\right)$, hemoglobin level, and lactate concentration.

Group data are given as mean \pm SEM. Differences between dependent variables were analyzed by Wilcoxon signed rank test (SigmaStat; Systat Software Inc, San Jose, Calif). The Spearman coefficient of correlation ( $\left.r \_s\right)$ was calculated to test correlations between parameters, and linear regression analysis was performed (SigmaPlot; Systat).

\section{Results}

Regional tissue oxygenations during CPB were determined in 9 female and 11 male patients with a mean age of $5.3 \pm 3.1$ months (range 3 days -10 months) and a mean body weight of $5.4 \pm 1.8 \mathrm{~kg}$ (range $3.2-9.5 \mathrm{~kg}$ ). Eight procedures were performed under conditions of normothermia, 7 under conditions of mild hypothermia at a core temperature of $32^{\circ} \mathrm{C}$, and the remaining 5 under conditions of moderate hypothermia at a core temperature of $28^{\circ} \mathrm{C}$. The mean duration of CPB was $98 \pm 25$ minutes (range 35-185 minutes). For each measurement, regional TOI recordings were performed and three blood samples were obtained simultaneously from the inferior, the superior, and the mixed venous lines of the CPB circuit. On average, $2.75 \pm 0.22$ measurements were performed for each patient, depending on the duration of $\mathrm{CPB}$, yielding a total of 55 measurements overall.

Direct comparison of $\mathrm{SvO}_{2}$ values revealed a significantly lower $\mathrm{SvO}_{2}$ in blood samples retrieved from the superior relative to the inferior venous line (Figure 1,A). The notion that average blood oxygenation is lower in the upper than in the lower body compartment was confirmed by NIRS measurements yielding higher TOI values at the thigh than at the forehead (Figure 1, B). This regional heterogeneity in oxygenation is directly reflected in the metabolic level by higher lactate concentrations in venous blood from the upper than in the lower torso (Figure 1,C). Thus regional oxygen extraction during CPB is higher in the upper body than in the lower body, and direct measurements of $\mathrm{SvO}_{2}$ or lactate in blood sampled from the mixed venous line of the CPB may overestimate the critical oxygenation status of the cerebral compartment.

To assess whether $\mathrm{S}_{\bar{v}} \mathrm{O}_{2}$ measurements yield an adequate estimate of the quality of perfusion and oxygenation in the different body compartments, we compared $\mathrm{SvO}_{2}$ data derived from the superior and inferior venous lines with simultaneously measured $\mathrm{S}_{\bar{v}} \mathrm{O}_{2}$ values (Figure 2). Although $\mathrm{S}_{\bar{v}} \mathrm{O}_{2}$ values were correlated linearly $\left(r \_\mathrm{s}=0.90, P<.001\right)$ with $\mathrm{SvO}_{2}$ measurements from the inferior venous line, no correlation was found between $\mathrm{S}_{\bar{v}} \mathrm{O}_{2}$ and $\mathrm{SvO}_{2}$ values determined simultaneously in the superior venous line of the CPB circuit. Thus $\mathrm{S}_{\bar{v}} \mathrm{O}_{2}$ yields a good estimate of the oxygenation status in the lower body but is of little predictive value regarding the upper body. This notion was further substantiated by the finding that lactate concentrations in mixed venous blood correlated significantly $\left(r \_s=0.32, P=0.018\right)$ with $\mathrm{SvO}_{2}$ values from the inferior but not the superior venous line.

A similar pattern of correlation was observed when $\mathrm{S}_{\bar{v}} \mathrm{O}_{2}$ values were compared with data on regional tissue oxygenation as determined by NIRS (Figure 3). Whereas $\mathrm{S}_{\bar{v}}{ }_{2}$ was correlated linearly $\left(r \_s=0.47, P<.001\right)$ with regional 


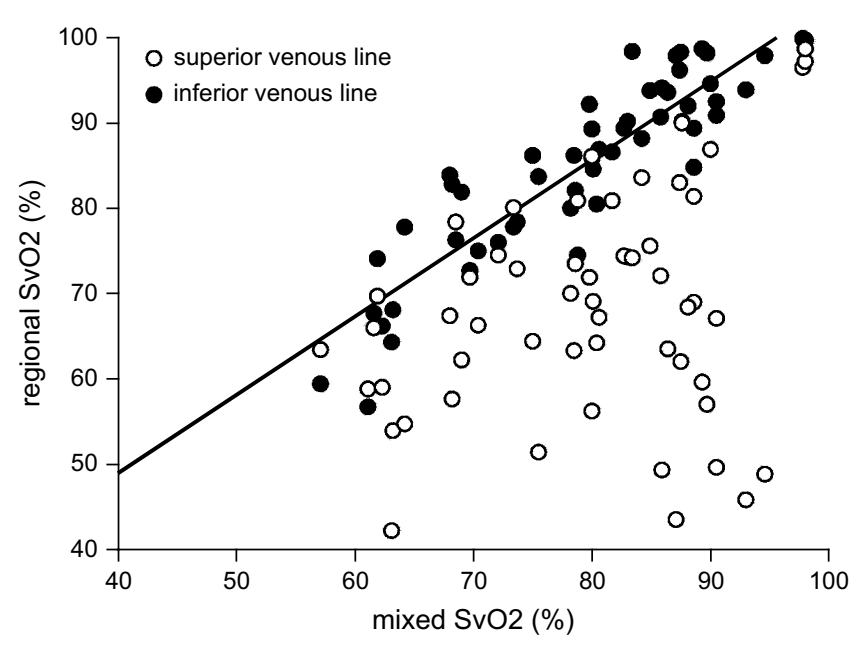

Figure 2. Correlations of mixed venous oxygen saturation $\left(\mathrm{Svo}_{2}\right)$ with values measured simultaneously in blood drawn from either superior cannula (open circles) or inferior cannula (closed circles) of cardiopulmonary bypass circuit. In 55 measurements each from 20 patients, mixed venous oxygen saturations were correlated significantly with values from inferior venous cannula ( $r \_s=0.897, P<.001$ ) but not from superior venous cannula.

TOI determined at the right thigh, no correlation with cerebral TOI values measured at the forehead was detectable. Thus $\mathrm{S}_{\bar{v}}{ }_{2}$ may reflect the oxygenation status in the lower torso but is a poor indicator of cerebral perfusion and oxygenation during $\mathrm{CPB}$ in neonates.

Cerebral oxygenation status can be adequately reflected by $\mathrm{SvO}_{2}$ if measurements are performed in venous blood from the upper body (Figure 4). This was evident from a linear correlation of cerebral tissue oxygenation determined by NIRS with $\mathrm{SvO}_{2}$ values determined simultaneously in the superior venous line $\left(r \_s=0.70, P<.001\right)$. Similarly, $\mathrm{SvO}_{2}$ values in the inferior venous line were correlated significantly with TOI data from the lower limb $\left(r \_s=0.56, P<\right.$ $.001)$. These findings confirm the validity of NIRS as a noninvasive technique for monitoring regional tissue oxygenation during $\mathrm{CPB}$ in neonates.

\section{Discussion}

We assessed regional differences in oxygenation in neonates and small infants during CPB for the correction of CHD with online-measured $\mathrm{S}_{\bar{v}}{ }_{2}$, regional $\mathrm{SvO}_{2}$, and regional TOI obtained with NIRS. Our data demonstrate that even with standard surgical and CPB procedures, considerable variations in tissue oxygenation exist between different body compartments. Importantly, $\mathrm{S}_{\bar{v}} \mathrm{O}_{2}$, which is widely used as a measure of adequacy of perfusion and oxygenation on $\mathrm{CPB},{ }^{19}$ was shown to reflect poorly the oxygenation status of the upper body compartment, including the brain. In contrast, noninvasive regional monitoring of tissue oxygenation by transcra-

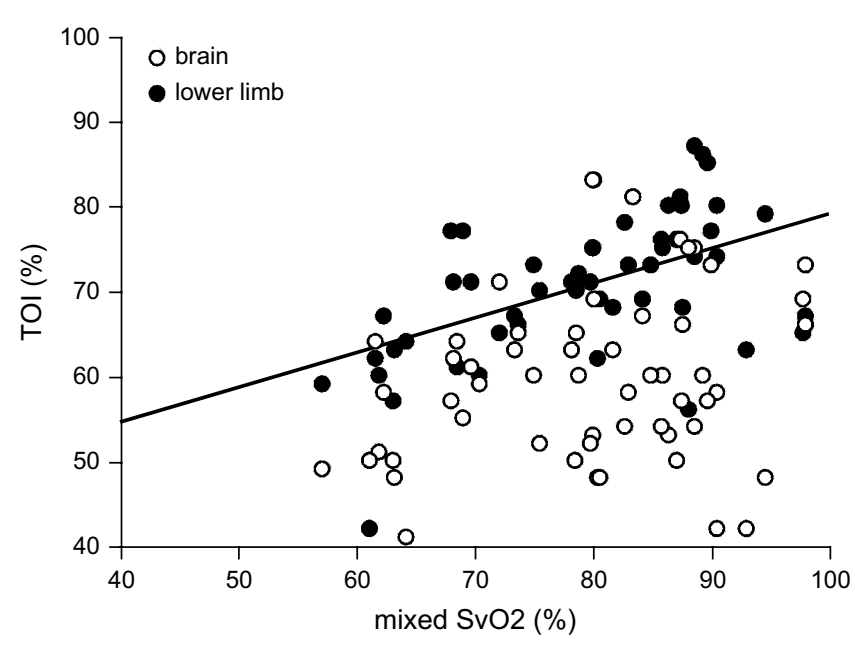

Figure 3. Correlations of mixed venous oxygen saturation $\left(\mathrm{SvO}_{2}\right)$ in cardiopulmonary bypass circuit with tissue oxygenation index (TOI) values measured simultaneously in either brain (open circles) or lower limb (closed circles) by regional near-infrared spectroscopy. In 55 measurements each from 20 patients, mixed venous oxygen saturation was correlated significantly with regional tissue oxygenation of lower limb $\left(r \_s=0.47, P<.001\right)$ but not of brain.

nial and lower-torso NIRS revealed significant correlations with $\mathrm{SvO}_{2}$ values measured in blood from the superior and inferior caval lines, respectively, thus yielding reliable information about the quality of regional perfusion and oxygenation during $\mathrm{CPB}$.

Our data demonstrate that in neonates and small infants undergoing surgery with $\mathrm{CPB}$ for the correction of $\mathrm{CHD}, \mathrm{S}_{\bar{v}} \mathrm{O}_{2}$ represents predominantly the oxygenation status in the lower body compartment drained by the caval vein inferior line of the CPB circuit, whereas the oxygenation status of the upper body, and particularly the brain, is poorly reflected. This deficiency in monitoring is even more detrimental because relative perfusion is on average worse in the upper body during $\mathrm{CPB}$, as reflected by lower $\mathrm{SvO}_{2}$ and higher lactate concentration. $\mathrm{S}_{\overline{\mathrm{V}}} \mathrm{O}_{2}$ thus systematically overestimates the adequacy of oxygenation and perfusion in the most critical organ, the brain, and serious cerebral malperfusion may remain unrecognized with the standard monitoring techniques.

Previous clinical studies evaluating the value of postoperative $\mathrm{S}_{\overline{\mathrm{v}}} \mathrm{O}_{2}$ monitoring in neonates and infants have shown conflicting results. In several independent studies, regional cerebral oxygenation assessed by NIRS was correlated significantly with $\mathrm{SvO}_{2}$ measured through a central venous or pulmonary arterial catheter. ${ }^{12,20,21}$ Surprisingly, the correlation between cerebral TOI and $\mathrm{S}_{\overline{\mathrm{V}}} \mathrm{O}_{2}$ was particularly high when the central venous catheter was placed with the tip in the inferior as opposed to the superior caval vein or the right 


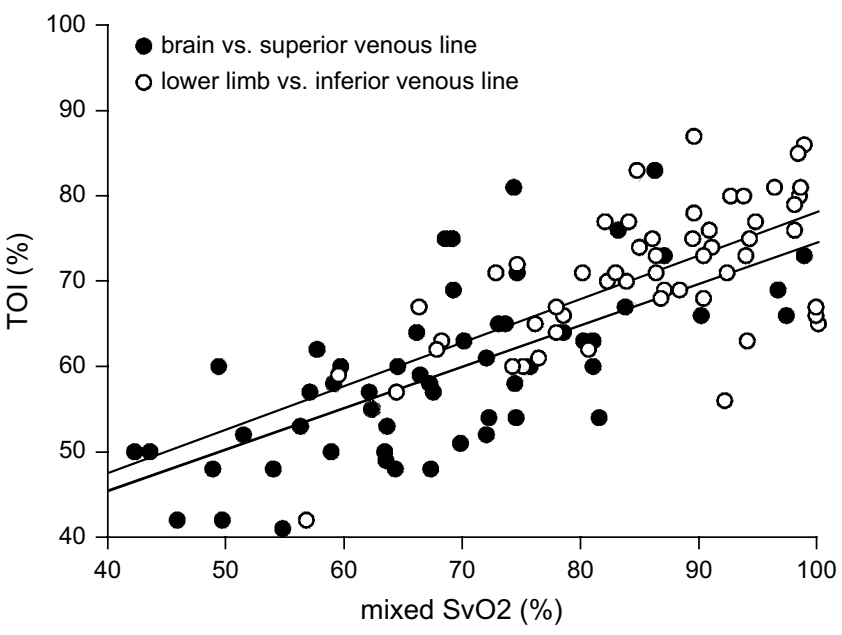

Figure 4. Correlations of regional venous oxygen saturation $\left(\mathrm{Svo}_{2}\right)$ determined in superior (closed circles) or inferior (open circles) cannula of cardiopulmonary bypass circuit with regional tissue oxygenation index (TOI) measured simultaneously by regional near-infrared spectroscopy in either brain (closed circles) or lower limb (open circles), respectively. In 55 measurements each from 20 patients, regional venous oxygen saturation was correlated significantly with regional tissue oxygenation index in both upper body $\left(r_{-} s=0.70, P<.001\right)$ and lower torso $\left(r_{-} s=\right.$ $0.56, P<.001)$.

atrium. ${ }^{21}$ Moreover, a Bland-Altman comparison between $\mathrm{S} \overline{\mathrm{v}}_{2}$ and regional oxygen saturation revealed wide limits of agreement, suggesting that despite a significant correlation $\mathrm{S}_{\overline{\mathrm{V}}} \mathrm{O}_{2}$ was of poor predictive value for cerebral oxygenation. ${ }^{12}$

During CPB, the adequacy of $\mathrm{S}_{\bar{v}} \mathrm{O}_{2}$ measurements to yield relevant information on the cerebral oxygenation status appears to be even further reduced. In our study, $\mathrm{S}_{\bar{v}} \mathrm{O}_{2}$ was correlated neither with cerebral TOI values determined by NIRS nor with $\mathrm{SvO}_{2}$ values from the superior venous line. This finding is in agreement with previous studies reporting a lack of correlation between $\mathrm{Sv}_{2} \mathrm{O}_{2}$ and jugular $\mathrm{SvO}_{2}$ in both pediatric ${ }^{19}$ and adult ${ }^{22}$ patients undergoing CPB. The perception that $\mathrm{S}_{\overline{\mathrm{V}}} \mathrm{O}_{2}$ provides only an unsatisfactory estimate of the cerebral oxygenation status during $\mathrm{CPB}$ is also supported by data from an experimental CPB model in swine, in which oxygenation in the sagittal sinus decreased from $66 \% \pm 3 \%$ to $33 \%$ $\pm 2 \%$, whereas $\mathrm{S}_{\overline{\mathrm{v}}} \mathrm{O}_{2}$ remained largely unchanged between $75 \%$ and $80 \%{ }^{10}$ Our finding that $\mathrm{S}_{\overline{\mathrm{v}}} \mathrm{O}_{2}$ represents primarily the lower body compartment during $\mathrm{CPB}$ is, furthermore, in agreement with a previous study by Lindholm and colleagues, ${ }^{10}$ who showed that $\mathrm{S}_{\bar{v}} \mathrm{O}_{2}$ correlates well with hepatic but not jugular vein oxygen saturation in adults undergoing $\mathrm{CPB}$. This study therefore shows, in line with previous reports, the existence of considerable regional heterogeneities in oxygenation in neonates and infants during $\mathrm{CPB}$, thus stressing the need for direct monitoring of critical organs at a local level.
Noninvasive monitoring of regional tissue oxygenation by NIRS may provide such crucial information. In our study, cerebral TOI measured by NIRS was correlated significantly with $\mathrm{SvO}_{2}$ determined simultaneously in the superior venous line, with a correlation coefficient of 0.70 . This is in agreement with previous studies demonstrating significant correlations between jugular bulb oxygen saturation and cerebral oxygenation determined by transcranial NIRS in children. ${ }^{23,24}$ The validity of the transcranial NIRS approach in yielding adequate and reliable information on cerebral oxygenation is further supported by data from Al-Rawi and coworkers ${ }^{25}$ who demonstrated an $87.5 \%$ sensitivity and a $100 \%$ specificity of the TOI measurement with respect to changes in intracranial perfusion in the adult head.

The interpretation of NIRS data is limited, however, by the technical constraints of the technique and the lack of reliable reference values or critical thresholds in defined patient populations. Approximately $70 \%$ of the obtained NIRS signal is derived from the venous compartment, with capillaries and arterioles contributing $20 \%$ and $10 \%$, respectively. ${ }^{26}$ TOI thus reflects $\mathrm{SvO}_{2}$ in the cerebral compartment only partially, varying not only with changes in tissue perfusion or oxygen extraction but also with changes in the relative distribution of blood volume among the arteriolar, capillary, and venous compartments within the scanned tissue section. Taking this into account, variations in TOI monitored by transcranial NIRS can still yield critical information on changes in the cerebral oxygenation status. The clinical relevance of NIRS monitoring is, however, further complicated by the lack of accepted and validated critical thresholds for cerebral TOI. This applies in particular to the patient population of neonates and small infants monitored in our study. In a recent clinical investigation of 143 infants and children undergoing CHD surgery, Fenton and coworkers ${ }^{27}$ showed an association of baseline cerebral oxygenation values of less than $50 \%$ with perioperative death, suggesting that postponement of the surgical intervention or additional interventions such as red blood cell transfusions or hyperoxic ventilation might be warranted in cases with preoperative TOI values below this threshold. Under perioperative conditions including $\mathrm{CPB}$, regional perfusion, and hypothermia, however, critical oxygenation thresholds in the brain remain largely unknown. This applies in particular to the patient population undergoing correction of CHD, in which individual susceptibility to tissue hypoxia may vary according to the underlying malformation and especially differs between cyanotic and noncyanotic malformations.

The high incidence and critical outcome of neurologic sequelae warrant optimization of cerebral monitoring during $\mathrm{CPB}$ in neonates and small infants. ${ }^{2-4}$ The results of our study demonstrate that the measurement of $\mathrm{S}_{\overline{\mathrm{v}}} \mathrm{O}_{2}$ is inadequate for this purpose and should be supplemented with additional monitoring systems with higher regional resolution. Currently, NIRS provides the only versatile noninvasive 
technique for point-of-care monitoring during CPB. The extent to which improved regional monitoring of oxygenation in neonates and small infants with CHD undergoing CPB can serve as a perioperative guidance tool to optimize cerebral perfusion and improve clinical outcome remains to be determined in future studies.

We thank Argit and Raimund Rutenberg for excellent technical assistance, and Anne M. Gale, Editor in Life Sciences, for editorial support.

\section{References}

1. Welke KF, Shen I, Ungerleider RM. Current assessment of mortality rates in congenital cardiac surgery. Ann Thorac Surg. 2006;82:164-70.

2. Austin EH 3rd, Edmonds HL Jr, Auden SM, Seremet V, Niznik G, Sehic A, et al. Benefit of neurophysiologic monitoring for pediatric cardiac surgery. J Thorac Cardiovasc Surg. 1997;114:707-17.

3. Majnemer A, Limperopoulos C, Shevell M, Rosenblatt B, Rohlicek C, Tchervenkov C. Long-term neuromotor outcome at school entry of infants with congenital heart defects requiring open-heart surgery. $J$ Pediatr. 2006;148:72-7.

4. Hövels-Gürich HH, Konrad K, Skorzenski D, Herpertz-Dahlmann B, Messmer BJ, Seghaye MC. Attentional dysfunction in children after corrective cardiac surgery in infancy. Ann Thorac Surg. 2007;83:1425-30.

5. Ballweg JA, Wernovsky G, Gaynor JW. Neurodevelopmental outcomes following congenital heart surgery. Pediatr Cardiol. 2007;28:126-33.

6. Majnemer A, Limperopoulos C, Shevell M, Rohlicek C, Rosenblatt B, Tchervenkov C. Health and well-being of children with congenital cardiac malformations, and their families, following open-heart surgery. Cardiol Young. 2006;16:57-164.

7. McQuillen PS, Barkovich AJ, Hamrick SE, Perez M, Ward P, Glidden DV, et al. Temporal and anatomic risk profile of brain injury with neonatal repair of congenital heart defects. Stroke. 2007;38:736-41.

8. Swan H, Sanchez M, Tyndall M, Koch C. Quality control of perfusion: monitoring venous blood oxygen tension to prevent hypoxic acidosis. J Thorac Cardiovasc Surg. 1990;99:868-72.

9. Lindholm L, Hansdottir V, Lundqvist M, Jeppsson A. The relationship between mixed venous and regional venous oxygen saturation during cardiopulmonary bypass. Perfusion. 2002;17:133-9.

10. McDaniel LB, Zwischenberger JB, Vertrees RA, Nutt L, Uchida T, Nguyen T, et al. Mixed venous oxygen saturation during cardiopulmonary bypass poorly predicts regional venous saturation. Anesth Analg. 1995;80:466-72.

11. Andropoulos DB, Stayer SA, Diaz LK, Ramamoorthy C. Neurological monitoring for congenital heart surgery. Anesth Analg. 2004;99: 1365-75.

12. McQuillen PS, Nishimoto MS, Bottrell CL, Fineman LD, Hamrick SE, Glidden DV, et al. Regional and central venous oxygen saturation monitoring following pediatric cardiac surgery: concordance and association with clinical variables. Pediatr Crit Care Med. 2007;8:154-60.
13. Wartenburger I, Steinbrink J, Telkemeyer S, Friedrich M, Friederici AD, Obrig $\mathrm{H}$. The processing of prosody: evidence of interhemispheric specialization at the age of four. Neuroimage. 2007;34:416-25.

14. Redlin M, Boettcher W, Huebler M, Berger F, Hetzer R, Koster A, et al. Detection of lower torso ischemia by near-infrared spectroscopy during cardiopulmonary bypass in a 6.8-kg infant with complex aortic anatomy. Ann Thorac Surg. 2006;82:323-5.

15. van der Zee P, Cope M, Arridge SR, Essenpreis M, Potter LA, Edwards $\mathrm{AD}$, et al. Experimentally measured optical pathlengths for the adult head, calf and forearm and the head of the newborn infant as a function of inter optode spacing. Adv Exp Med Biol. 1992;316:143-53.

16. Matcher SJ, Kirkpatrick PJ, Nahid K, Cope M, Delpy DT. Absolute quantification methods in tissue near infrared spectroscopy. Proc SPIE. 1995;2389:486-95.

17. Suzuki S, Takasaki S, Ozaki T, Kobayashi Y. A tissue oxygenation monitor using NIR spatially resolved spectroscopy. Proc SPIE. 1999;3597: 582-92.

18. Huebler M, Boettcher W, Koster A, Stiller B, Kuppe H, Hetzer R. Transfusion-free cardiac reoperation in an 11-kg Jehovah's Witness child by use of a minimized cardiopulmonary bypass circuit. Tex Heart Inst J. 2007;34:108-11.

19. Yeh T Jr, Gouldman J, Auden SM, Seremet V, Edmonds HL Jr, Cerrito PB, et al. Mixed venous oxygen saturation does not adequately predict cerebral perfusion during pediatric cardiopulmonary bypass. J Thorac Cardiovasc Surg. 2001;122:192-3.

20. Tortoriello TA, Stayer SA, Mott AR, McKenzie ED, Fraser CD, Andropoulos DB, et al. A noninvasive estimation of mixed venous oxygen saturation using near-infrared spectroscopy by cerebral oximetry in pediatric cardiac surgery patients. Paediatr Anaesth. 2005;15: 495-503.

21. Weiss M, Dullenkopf A, Kolarova A, Schulz G, Frey B, Baenziger O. Near-infrared spectroscopic cerebral oxygenation reading in neonates and infants is associated with central venous oxygen saturation. Paediatr Anaesth. 2005;15:102-9.

22. Croughwell ND, White WD, Smith LR, Davis RD, Glower DD Jr, Reves JG, et al. Jugular bulb saturation and mixed venous saturation during cardiopulmonary bypass. J Card Surg. 1995;10(4 Suppl):503-8.

23. Daubeney PE, Pilkington SN, Janke E, Charlton GA, Smith DC, Webber SA. Cerebral oxygenation measured by near-infrared spectroscopy: comparison with jugular bulb oximetry. Ann Thorac Surg. 1996; 61:930-4.

24. Nagdyman N, Fleck T, Schubert S, Ewert P, Peters B, Lange PE, et al. Comparison between cerebral tissue oxygenation index measured by near-infrared spectroscopy and venous jugular bulb saturation in children. Intensive Care Med. 2005;31:846-50.

25. Al-Rawi PG, Smielewski P, Kirkpatrick PJ. Evaluation of a near-infrared spectrometer (NIRO 300) for the detection of intracranial oxygenation changes in the adult head. Stroke. 2001;32:2492-500.

26. Boushel R, Langberg H, Olesen J, Gonzales-Alonzo J, Bülow J, Kjaer M. Monitoring tissue oxygen availability with near infrared spectroscopy (NIRS) in health and disease. Scand J Med Sci Sports. 2001;11: 213-22.

27. Fenton KN, Freeman K, Glogowski K, Fogg S, Duncan KF. The significance of baseline cerebral oxygen saturation in children undergoing congenital heart surgery. Am J Surg. 2005;190:260-3. 